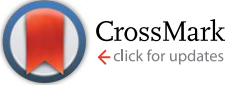

Cite this: RSC Adv., 2017, 7, 3051

Received 21st October 2016 Accepted 30th November 2016

DOI: $10.1039 / c 6 r a 25583 c$

www.rsc.org/advances

\title{
On-off-on fluorescent oligomer as a chemosensor for the detection of manganese(VII), sulfur(II) and aldehydes based on the inner filter effect $\uparrow$
}

\author{
Peng Ding, ${ }^{\text {ab }}$ Xia Xin, ${ }^{* a c}$ Lingli Zhao, ${ }^{a}$ Zengchun Xie, ${ }^{a}$ Qinghong Zhang, ${ }^{\text {ab }}$ \\ Jianmei Jiao ${ }^{a}$ and Guiying $\mathrm{Xu}^{\mathrm{ac}}$
}

\begin{abstract}
In this article, a sensitive and selective on-off-on fluorescence chemosensor, Tyloxapol (one kind of water soluble oligomer), was developed for the label-free detection of $\mathrm{MnO}_{4}{ }^{-}$ions in aqueous solution. From fluorescence experiments, it is demonstrated that Tyloxapol is a sensitive and selective fluorescence sensor for the detection of $\mathrm{MnO}_{4}{ }^{-}$directly in water over a wide range of anions including $\mathrm{Cl}^{-}, \mathrm{Br}^{-}, \mathrm{I}^{-}$, $\mathrm{NO}_{3}{ }^{-}, \mathrm{H}_{2} \mathrm{PO}_{4}^{-}, \mathrm{HCO}_{3}{ }^{-}, \mathrm{OH}^{-}, \mathrm{ClO}_{4}{ }^{-}, \mathrm{Ac}^{-}, \mathrm{SO}_{4}{ }^{2-}, \mathrm{HPO}_{4}{ }^{2-}, \mathrm{CO}_{3}{ }^{2-}, \mathrm{C}_{2} \mathrm{O}_{4}{ }^{2-}, \mathrm{S}^{2-}, \mathrm{SO}_{3}^{2-}$, and $\mathrm{Cr}_{2} \mathrm{O}_{7}{ }^{2-}$. Moreover, the fluorescence intensity of Tyloxapol has shown a linear response to $\mathrm{MnO}_{4}{ }^{-}$in the

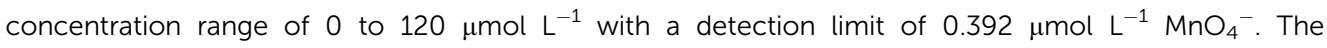
interaction mechanism demonstrated that our on-off fluorescent oligomer probe for detecting $\mathrm{Mn}(\mathrm{VII})$ is based on the inner filter effect (IFE) because the absorption bands of $\mathrm{Mn}(\mathrm{VII})$ are fully covered by the excitation bands of Tyloxapol. Next, another turn-on sensing application of the Tyloxapol/ $/ \mathrm{MnO}_{4}{ }^{-}$ platform to probe $\mathrm{S}^{2-}$ against various other anions and aldehydes against various other organic pollutants were also established. It is expected that our strategy may offer a new approach for developing a simple, cost-effective, rapid and sensitive sensor for the detection of anions and aldehydes in environmental applications.
\end{abstract}

\section{Introduction}

Anions widely exist in nature and living organisms, are closely related to human survival and development, and play an important role in medicine, catalysis, environmental science and other fields. ${ }^{1-3}$ Due to the importance of anions in pharmacy and biological science, the design and synthesis of efficient anion receptors has attracted the intensive interest of scientists. $^{4,5}$ Compared with cations, anions have their own features, such as the radius of an anion is larger than a cation that has the same charge, the electrostatic attraction between a probe molecule and an anion is weaker than that between a probe molecule and a cation; an anion has a different geometry and the solvent effect has a great influence on the binding properties and selectivity of the anion; an anion is sensitive to the $\mathrm{pH}$ of solution, so the detection of anions must occur under a suitable $\mathrm{pH}$ environment. ${ }^{6-8}$

${ }^{a}$ National Engineering Technology Research Center for Colloidal Materials, Shandong University, Jinan, 250100, P. R. China. E-mail: xinx@sdu.edu.cn; Fax: +86-53188361008; Tel: +86-531-88363597

${ }^{b}$ China Research Institute of Daily Chemical Industry, Taiyuan, Shanxi, 030001, P. R. China

'Key Laboratory of Colloid and Interface Chemistry (Shandong University), Ministry of Education, Jinan, 250100, P. R. China

$\dagger$ Electronic supplementary information (ESI) available. See DOI: $10.1039 / \mathrm{c} 6 \mathrm{ra} 25583 \mathrm{c}$
Due to the development of industry, industrial and other anthropogenic processes have been releasing heavy-metal ions into the environment, such as $\mathrm{Cr}$ and $\mathrm{Mn} .{ }^{9-11}$ Among them, $\mathrm{Mn}(\mathrm{VII})$ is more hazardous to public health compared to other valence states, such as $\mathrm{Mn}$ (II) and $\mathrm{Mn}(\mathrm{VI})$, because of its greater stability and carcinogenic properties. For example, as for anion pollutants, $\mathrm{MnO}_{4}{ }^{-}$is the most commonly used strong oxidant in both laboratory and industrial applications and $\mathrm{MnO}_{4}{ }^{-}$has received great attention because it can cause severe damage to human health and the environment, which is a worldwide problem that is listed as a priority by the U.S. Environmental Protection Agency. ${ }^{\mathbf{1 2 , 1 3}}$ Therefore, the determination of Mn(VII) in environmental samples is of great importance. ${ }^{14,15}$ There are many methods to detect $\mathrm{MnO}_{4}{ }^{-}$, such as flame atomic absorption spectrophotometry and potassium periodate spectrophotometry, and the detection limit of luminescent probes to detect $\mathrm{MnO}_{4}{ }^{-}$could low as $0.28 \mu \mathrm{M.}^{16}$

Moreover, aldehydes are widely used industrial raw material, mainly used in wood industry, textile industry, pesticides, dyes, etc. Formaldehyde is a strong pungent smell of gas, will bring great harm to the human body. ${ }^{17}$ The main harm of formaldehyde is the stimulation of the skin and mucous membranes. When it reach a certain concentration in room can make people feel uncomfortable, identified as first class of carcinogens in 2006. So the determination of aldehyde in environmental samples is of great importance. ${ }^{18,19}$ Different kinds of gas 
sensing approaches have been used to measure aldehyde concentrations in air: such as cataluminescence, ${ }^{20}$ gas chromatography, ${ }^{21}$ chemoresistivity (inorganic, ${ }^{22}$ organic, ${ }^{23}$ and hybrid $^{24}$ materials), chemocapacitance, ${ }^{25}$ bio-sensing, ${ }^{26}$ amperometric electrochemical cells, ${ }^{27}$ etc.

Besides, sulfur dioxide $\left(\mathrm{SO}_{2}\right)$ and its derivatives has vastly produced by the combustion of coal and fuels, exposure to $\mathrm{SO}_{2}$ not only creates breathing problems but also and induce respiratory diseases, even if cancers. ${ }^{28,29}$ Sulfur ions can exist stable in neutral and alkaline aqueous solution, but it can easily become to hydrogen sulfide under acidic conditions via chemical reaction. Hydrogen sulfide is an extremely malodorous toxic and corrosive gas, which can lead to olfactory fatigue, resulting in the loss of the sense of the sulfide smell. ${ }^{30,31}$ Once water containing concentration which is higher than $0.5-1 \mathrm{mg} \mathrm{L}^{-1}$ can poison fish. Nevertheless, the design of suitable fluorescent probe for sulfur and sulfate are also challenging. A variety of detection techniques have been developed for the determination of sulfide anion, ${ }^{32}$ such as titration,,$^{33}$ spectrophotometry, ${ }^{34}$ inductively coupled plasma atomic emission spectroscopy (ICPAES), ${ }^{35}$ electrochemical methods, ${ }^{36}$ fluorimetry ${ }^{37}$ and chemiluminescence methods $\mathrm{s}^{38}$ and the detection limit of $\mathrm{S}^{2-}$ and formaldehyde can low as $0.48 \mu \mathrm{M}$ (ref. 39) and $36 \mu \mathrm{M}$ (ref. 40) in the reported article, respectively.

Thus, it can be seen that until now, there are many methods for the detection of $\mathrm{MnO}_{4}{ }^{-}, \mathrm{S}^{2-}$ and formaldehyde as mentioned above, however, these methods are time-consuming and the equipment requirements are high which can't meet the needs of the current analysis. Compared with these conventional methods, fluorescence (FL) detection has been widely used as a versatile tool in analytical chemistry, biochemistry and cell biology due to its high sensibility, specificity, and realtime monitoring with fast response time. ${ }^{\mathbf{4 1 - 4 4}}$ Thus, in this article, a highly sensitive and selective on-off-on fluorescence chemosensor, Tyloxapol (one kind of water soluble oligomer), was developed for the detection of $\mathrm{MnO}_{4}{ }^{-}$and $\mathrm{S}^{2-}$ in aqueous solution. Moreover, it can also be used to probe aldehydes against various other organic pollutants. Thus, it is expected that our system can be used as a promising sensor for $\mathrm{MnO}_{4}{ }^{-}$, $\mathrm{S}^{2-}$ and aldehydes that appear as pollutants in the environment.

\section{Experimental section}

\section{Chemicals and materials}

Tyloxapol, were purchased from Sigma-Aldrich. The chemical structure of Tyloxapol was shown in Fig. 1. All the metal salts used in this work including $\mathrm{NaCl}, \mathrm{NaBr}, \mathrm{NaI}, \mathrm{NaNO}_{3}, \mathrm{NaH}_{2} \mathrm{PO}_{4}$, $\mathrm{NaHCO}_{3}, \mathrm{NaClO}_{4}, \mathrm{NaAc}, \mathrm{Na}_{2} \mathrm{SO}_{4}, \mathrm{Na}_{2} \mathrm{HPO}_{4}, \mathrm{Na}_{2} \mathrm{CO}_{3}, \mathrm{Na}_{2} \mathrm{C}_{2} \mathrm{O}_{4}$, $\mathrm{Na}_{2} \mathrm{~S}, \mathrm{Na}_{2} \mathrm{SO}_{3}, \mathrm{~K}_{2} \mathrm{Cr}_{2} \mathrm{O}_{7}, \mathrm{KMnO}_{4}$ and other organics such as aniline, phenol, formaldehyde, glyoxal were all purchased from Sinopharm Chemical Reagent Co. All the above reagents were used without further purification. Ultra-pure water used in the experiments was triply distilled by a quartz water purification system. Its conductivity was lower than $1.8 \mu \mathrm{S} \mathrm{cm}^{-1}$ as measured by a DDSJ-308A type conductivity instrument in our laboratory.

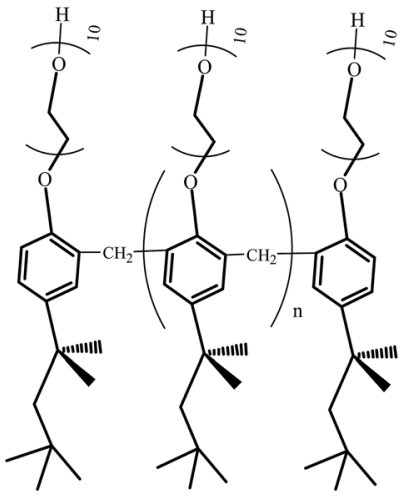

Tyloxapol, $\mathrm{n}=5, \mathrm{MW}=4611$

Fig. 1 The chemical structure of Tyloxapol.

\section{Methods and characterizations}

The FL measurements were performed on a LS-55 spectrofluorometer (PerkinElmer, Waltham, MA, USA) with a quartz cell (1 $\times 1 \mathrm{~cm}$ ). For transmission electron microscopy (TEM) observations, about $5 \mu \mathrm{L}$ of solution was placed on a TEM grid and the excess solution was wicked away with filter paper. The copper grid was freeze-dried and observed on a JEOL JEM-100 CXII (Japan) at an accelerating voltage of $80 \mathrm{kV}$. The quantum yield and fluorescence lifetimes were measured on a FLS920 with a time correlated single photon counting (TCSPC) method by excitation with $360 \mathrm{~nm}$. The absolute fluorescence quantum yields were measured with an integrating sphere. The fluorescence lifetimes were measured on a FLS920 with a time correlated single photon counting (TCSPC) method by excitation with $360 \mathrm{~nm}$. The data were deconvoluted with the instrument response function, recorded using dispersed light, and fitted to a multi-exponential function. The absolute fluorescence quantum yields were measured with an integrating sphere.

\section{Detection of $\mathrm{MnO}_{4}^{-}$}

In a typical assay, Tyloxapol solution was added into ultra-pure water (the final concentration of Tyloxapol was fixed at $3 \mathrm{mmol}$ $\mathrm{L}^{-1}$ ), followed by the addition of different concentrations of $\mathrm{MnO}_{4}{ }^{-}$ion. The FL spectra were recorded after reaction for $30 \mathrm{~min}$. The selectivity for $\mathrm{MnO}_{4}{ }^{-}$was confirmed by adding other anions stock solutions instead of $\mathrm{MnO}_{4}{ }^{-}$in a similar way. All experiments were performed at room temperature.

\section{Detection of $S^{2-}$}

In a typical assay, Tyloxapol and $\mathrm{MnO}_{4}{ }^{-}$ion solutions were added into ultra-pure water (the final concentration of Tyloxapol and $\mathrm{MnO}_{4}{ }^{-}$were fixed at $3 \mathrm{mmol} \mathrm{L}^{-1}$ and $200 \mu \mathrm{mol} \mathrm{L}{ }^{-1}$ ), respectively, followed by the addition of $\mathrm{S}^{2-}$. The FL spectra were recorded after reaction for $30 \mathrm{~min}$. The selectivity for $\mathrm{S}^{2-}$ was confirmed by adding other related anions instead of $\mathrm{S}^{2-}$ in a similar way. All experiments were performed at room temperature. 


\section{Detection of aldehydes}

Tyloxapol and $\mathrm{MnO}_{4}{ }^{-}$ion solutions were added into ultra-pure water (the final concentration of Tyloxapol and $\mathrm{MnO}_{4}{ }^{-}$were fixed at $3 \mathrm{mmol} \mathrm{L}^{-1}$ and $200 \mu \mathrm{mol} \mathrm{L}{ }^{-1}$ ), respectively, followed by the addition of formaldehyde. The FL spectra were recorded after reaction for $30 \mathrm{~min}$. The selectivity for formaldehyde was confirmed by adding other organic pollutant. All experiments were performed at room temperature.

\section{Results and discussion}

\section{The fluorescent property of Tyloxapol}

It is well-known that Tyloxapol can be considered as an oligomer of the nonionic surfactant TX-100 with a polymerization degree below $7 .{ }^{45}$ In our previous experiment, it has been demonstrated that Tyloxapol has a luminescent property while for TX-100 aqueous solution, no FL has been detected. ${ }^{46}$ Thus, it can be concluded that the FL of Tyloxapol is ascribed to the close packing of the seven benzene rings which produces the $\pi-$ $\pi$ interaction between the aromatic rings of Tyloxapol while such effect is absent in TX-100. Moreover, the absolute photoluminescence quantum yield of Tyloxapol is $9 \%$ when the emission spectrum of Tyloxapol is at $360 \mathrm{~nm}$. It also can be seen from Fig. 2 that the UV/vis absorption spectrum shows a broad absorption band between $300-400 \mathrm{~nm}$ which is consistent with the $\pi-\pi^{*}$ transition of $\mathrm{C}=\mathrm{C}^{47}$ From a detailed photoluminescence study, it also can be found that as the excitation wavelength increases (Fig. 2 and $\mathrm{S} 1 \dagger$ ), the emission peak shifts to longer wavelength (from about $375 \mathrm{~nm}$ to about $445 \mathrm{~nm}$ with a dependence on the excitation wavelengths) and the intensity continually decreases and a very bright blue luminescence under the illumination of UV (365 nm) light can be clearly seen in the inset of Fig. 2.

In our previous study, it has been also demonstrated that with the increase of the concentration of Tyloxapol, the fluorescence

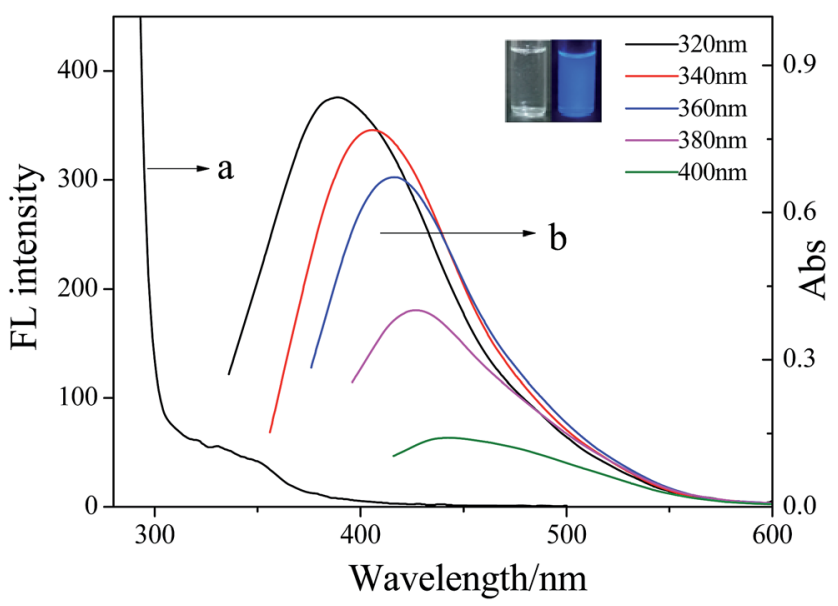

Fig. 2 UV-vis absorption spectra (a) and the FL emission spectra (b) of $3 \mathrm{mmol} \mathrm{L} \mathrm{L}^{-1}$ Tyloxapol recorded for progressively longer excitation wavelengths in $10 \mathrm{~nm}$ increments from $310 \mathrm{~nm}$ to $400 \mathrm{~nm}$. Inset: photographs taken under daylight (left) and $365 \mathrm{~nm}$ UV light (right) for 3 mmol L ${ }^{-1}$ Tyloxapol. intensity of Tyloxapol increased continually and when its concentration reached $0.02 \mathrm{mmol} \mathrm{L}^{-1}$, the fluorescence intensity increased sharply (Fig. S2a $\dagger$ ) which is nearly consistent with the cmc of Tyloxapol $\left(0.03 \mathrm{mmol} \mathrm{L}^{-1}\right)$ because of the formation of micelles. Moreover, the variation of the light scattering intensities as a function of the concentration of Tyloxapol (Fig. S2b $\dagger$ ) also indicates that the light scattering intensity increased sharply $\left(0.03 \mathrm{mmol} \mathrm{L}^{-1}\right)$ which is also nearly consistent with the cmc of Tyloxapol. This is because that the formation of micelles made the Tyloxapol molecules accumulating more closely and induced a stronger $\pi-\pi$ interaction and this phenomenon can be called aggregation-induced emission (AIE). ${ }^{48-50}$ Thus, in our next experiments, the concentration of Tyloxapol was still fixed at $3 \mathrm{mmol} \mathrm{L}^{-1}$ which is above the cmc of Tyloxapol and has strong fluorescence intensity which is benefit for further study.

\section{$\mathrm{MnO}_{4}{ }^{-}$detection by Tyloxapol}

In our previous study, it has been demonstrated that Tyloxapol was a sensitive and selective fluorescence sensor for the detection of $\mathrm{Fe}^{3+}$ directly in water over a wide range of metal cations including $\mathrm{Na}^{+}, \mathrm{K}^{+}, \mathrm{Ag}^{+}, \mathrm{Hg}^{2+}, \mathrm{Cd}^{2+}, \mathrm{Co}^{2+}, \mathrm{Cu}^{2+}, \mathrm{Cr}^{3+}, \mathrm{Mn}^{2+}, \mathrm{Ba}^{2+}$, $\mathrm{Zn}^{2+}, \mathrm{Ni}^{2+}, \mathrm{Mg}^{2+}, \mathrm{Ca}^{2+}$, and $\mathrm{Pb}^{2+}$. ${ }^{51}$ The possible mechanism of fluorescence quenching may be ascribed to the formation of complexes between Tyloxapol and $\mathrm{Fe}^{3+}$. Thus, in this paper, we want to test the sensitive and selective fluorescence behavior of Tyloxapol for a variety of different anions, including $\mathrm{Cl}^{-}, \mathrm{Br}^{-}$, $\mathrm{I}^{-}, \mathrm{NO}_{3}{ }^{-}, \mathrm{H}_{2} \mathrm{PO}_{4}{ }^{-}, \mathrm{HCO}_{3}{ }^{-}, \mathrm{OH}^{-}, \mathrm{ClO}_{4}{ }^{-}, \mathrm{Ac}^{-}, \mathrm{SO}_{4}{ }^{2-}, \mathrm{HPO}_{4}{ }^{2-}$, $\mathrm{CO}_{3}{ }^{2-}, \mathrm{C}_{2} \mathrm{O}_{4}{ }^{2-}, \mathrm{S}^{2-}, \mathrm{SO}_{3}{ }^{2-}, \mathrm{Cr}_{2} \mathrm{O}_{7}{ }^{2-}$ and $\mathrm{MnO}_{4}{ }^{-}$. Firstly, the sensing behavior of Tyloxapol $\left(3 \mathrm{mmol} \mathrm{L}^{-1}\right)$ by testing the changes of the fluorescence intensity was investigated by mixing it with different anions $\left(200 \mu \mathrm{mol} \mathrm{L}^{-1}\right)$ mentioned above. From the FL experimental results, it can be seen that no apparent FL signal changes of the solutions are observed with the addition of most anions as shown in Fig. 3A. However, the addition of $\mathrm{I}^{-}, \mathrm{Cr}_{2} \mathrm{O}_{7}{ }^{2-}$ and $\mathrm{MnO}_{4}{ }^{-}$affected the FL spectra and quenched the FL. Especially for $\mathrm{Cr}_{2} \mathrm{O}_{7}{ }^{2-}$ and $\mathrm{MnO}_{4}{ }^{-}$, an obvious FL decrease was observed and the emission intensity was quenched nearly $\sim 78 \%$ and $\sim 99 \%$, respectively.

The reason for $\mathrm{Cr}_{2} \mathrm{O}_{7}{ }^{2-}$ and $\mathrm{MnO}_{4}{ }^{-}$to quench the fluorescence of Tyloxapol may be because of inner filter effect (IFE). It is wellknown that a high efficiency of the IFE needs a good spectral overlap between the absorption band of the absorber and the excitation band or emission band of the fluorophore. ${ }^{52,53}$ Therefore, it is important to choose a suitable absorber and fluorophore pair for the IFE-based fluorescent chemosensor. ${ }^{54}$ As shown in Fig. 4A, the excitation wavelength of Tyloxapol has range from 310 to $360 \mathrm{~nm}$ (Fig. 4A, a), and the emission wavelength of Tyloxapol has range from 380 to $450 \mathrm{~nm}$ (Fig. 4A, b); however, Mn(vII) exhibits broad UV-vis absorption from 270 to $380 \mathrm{~nm}$ (Fig. 4B, a), fully covered the excitation band of Tyloxapol. UV-vis absorption of $\mathrm{Cr}(\mathrm{vI})$ can also partly cover the excitation band of Tyloxapol (Fig. 4B, b), which can explain when added $\mathrm{MnO}_{4}{ }^{-}$and $\mathrm{Cr}_{2} \mathrm{O}_{7}{ }^{2-}$ to Tyloxapol solution, the FL can quenching obviously. Therefore, the absorbance enhancement of Mn(vII) could be successfully converted to fluorescence quenching of Tyloxapol, which ensures that the IFE occurs in a highly efficient way. 

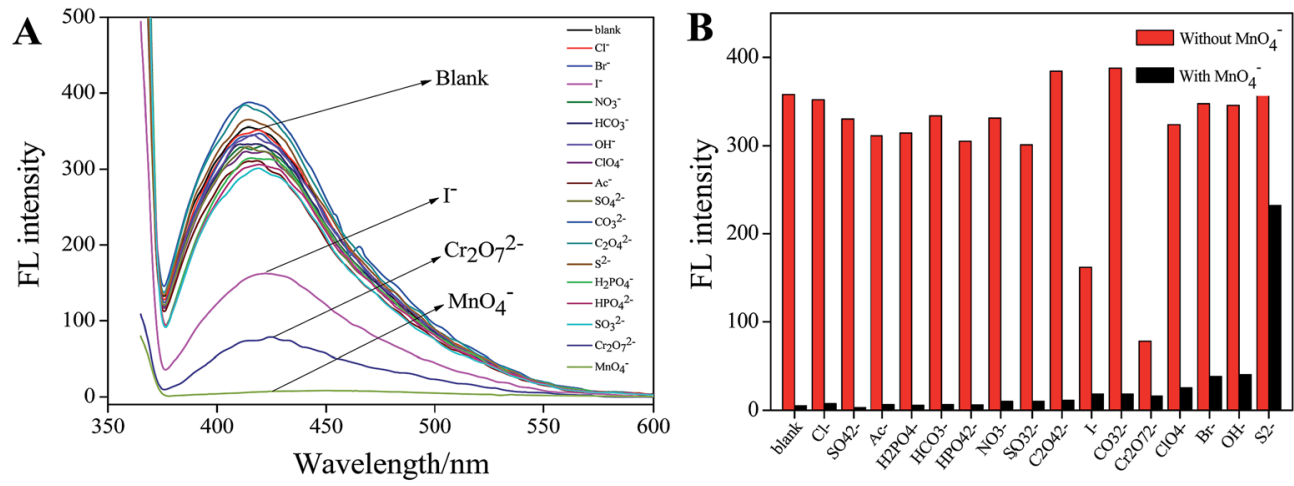

Blank $\mathrm{Cl}^{-} \quad \mathrm{Br}-\mathrm{I}^{-} \quad \mathrm{NO}_{3}^{-} \mathrm{OH}^{-} \mathrm{Ac}^{-} \mathrm{SO}_{4}{ }^{2-} \mathrm{SO}_{3}{ }^{2-} \mathrm{S}^{2-} \mathrm{Cr}_{2} \mathrm{O}_{7}{ }^{2-} \mathrm{MnO}_{4}^{-}$

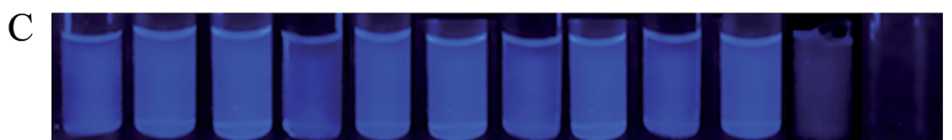

Fig. 3 (A) Change in fluorescence intensity of $3 \mathrm{mmol} \mathrm{L}^{-1}$ Tyloxapol upon addition of various anions including $\mathrm{Cl}^{-}, \mathrm{Br}^{-}, \mathrm{I}^{-}, \mathrm{NO}_{3}^{-}, \mathrm{H}_{2} \mathrm{PO}_{4}^{-}$, $\mathrm{HCO}_{3}{ }^{-}, \mathrm{OH}^{-}, \mathrm{ClO}_{4}{ }^{-}, \mathrm{Ac}^{-}, \mathrm{SO}_{4}{ }^{2-}, \mathrm{HPO}_{4}{ }^{2-}, \mathrm{CO}_{3}{ }^{2-}, \mathrm{C}_{2} \mathrm{O}_{4}{ }^{2-}, \mathrm{S}^{2-}, \mathrm{SO}_{3}{ }^{2-}, \mathrm{Cr}_{2} \mathrm{O}_{7}{ }^{2-}$ and $\mathrm{MnO}_{4}{ }^{-}$. (B) Selectivity of Tyloxapol toward $\mathrm{MnO}_{4}{ }^{-}$. Red bars represent the addition of various anions to the blank solution and black bars represent the subsequent addition of $\mathrm{MnO}_{4}{ }^{-}\left(200 \mu \mathrm{mol} \mathrm{L}^{-1}\right)$ to the above solutions (Tyloxapol $+\mathrm{A}^{n-}+\mathrm{MnO}_{4}^{-}$). Excitation wavelength $=360 \mathrm{~nm}$. (C) Photographs of the aqueous Tyloxapol containing $200 \mu \mathrm{mol}$ $\mathrm{L}^{-1}$ various anions under $365 \mathrm{~nm} \mathrm{UV}$ light. From left to right: blank, $\mathrm{Cl}^{-}, \mathrm{Br}^{-}, \mathrm{I}^{-}, \mathrm{NO}_{3}^{-}, \mathrm{OH}^{-}, \mathrm{Ac}^{-}, \mathrm{SO}_{4}^{2-}, \mathrm{SO}_{3}^{2-}, \mathrm{S}^{2-}, \mathrm{Cr}_{2} \mathrm{O}_{7}^{2-}$ and $\mathrm{MnO}_{4}^{-}$.
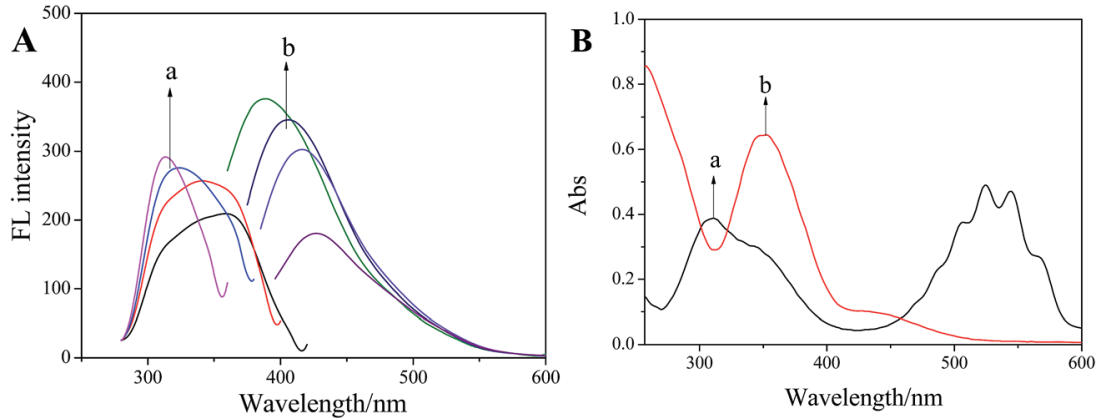

Fig. 4 (A) FL excitation (a) and emission (b) spectra of Tyloxapol (3 $\left.\mathrm{mmol} \mathrm{L}^{-1}\right)$ and (B) UV-vis absorption spectrum of $\mathrm{Mn}(\mathrm{VII})(\mathrm{a})$ and $\mathrm{Cr}(\mathrm{VI})$ (b).

Because $\mathrm{MnO}_{4}{ }^{-}$has the highest quenching efficiency of Tyloxapol, in our next study, we focus on $\mathrm{MnO}_{4}{ }^{-}$for further study. For an excellent chemosensor, high selectivity is a matter of necessity and an important evaluation index. ${ }^{55}$ The selectivity of Tyloxapol toward $\mathrm{MnO}_{4}{ }^{-}$was determined by contrast experiments of the $\mathrm{MnO}_{4}{ }^{-}$solutions mixed with other common anions $\mathrm{Cl}^{-}$, $\mathrm{Br}^{-}, \mathrm{I}^{-}, \mathrm{NO}_{3}{ }^{-}, \mathrm{H}_{2} \mathrm{PO}_{4}{ }^{-}, \mathrm{HCO}_{3}{ }^{-}, \mathrm{OH}^{-}, \mathrm{ClO}_{4}{ }^{-}, \mathrm{Ac}^{-}, \mathrm{SO}_{4}{ }^{2-}, \mathrm{HPO}_{4}{ }^{2-}$, $\mathrm{CO}_{3}{ }^{2-}, \mathrm{C}_{2} \mathrm{O}_{4}{ }^{2-}, \mathrm{S}^{2-}, \mathrm{SO}_{3}{ }^{2-}$ and $\mathrm{Cr}_{2} \mathrm{O}_{7}{ }^{2-}\left(200 \mu \mathrm{mol} \mathrm{L}{ }^{-1}\right)$ (Fig. $\left.\mathrm{S} 3 \dagger\right)$. In Fig. 3B, the black bars represent the fluorescence intensity of Tyloxapol in the presence of $\mathrm{MnO}_{4}{ }^{-}$in solution together with above individual anions. It can be seen that excepted $\mathrm{S}^{2-}, \mathrm{MnO}_{4}{ }^{-}$ showed high impact on the fluorescence intensity when compared to the red bars which correspond to the fluorescence intensity of a solution with the same anion in the absence of $\mathrm{MnO}_{4}{ }^{-}$. These results clearly demonstrate that the Tyloxapol-based $\mathrm{MnO}_{4}{ }^{-}$ sensor is highly sensitive and selective toward $\mathrm{MnO}_{4}{ }^{-}$in the presence of other common anions excepted $\mathrm{S}^{2-}$ in our study.

Then, the capability of Tyloxapol for quantitative detection of $\mathrm{MnO}_{4}{ }^{-}$was evaluated. As shown in Fig. 5A, the FL intensity of
Tyloxapol decreases gradually with increasing concentration of $\mathrm{MnO}_{4}{ }^{-}$, indicating that addition of $\mathrm{MnO}_{4}{ }^{-}$ions can effectively quench the fluorescence of Tyloxapol. Fig. 5B shows that the FL property change is the most sensitive as the $\mathrm{MnO}_{4}{ }^{-}$concentration increases from 10 to $100 \mu \mathrm{mol} \mathrm{L}^{-1}$ and then slows down with a further increase in $\mathrm{MnO}_{4}{ }^{-}$concentration. When the $\mathrm{MnO}_{4}{ }^{-}$ concentration is above $200 \mu \mathrm{mol} \mathrm{L}{ }^{-1}$, most of Tyloxapol molecules have been surrounded by $\mathrm{MnO}_{4}{ }^{-}$, and thus there is no big change in the FL property. Moreover, a good linear correlation $\left(R^{2}\right.$ $=0.997$ ) is observed over the concentration range of $0-120 \mu \mathrm{mol}$ $\mathrm{L}^{-1}$ and the detection limit (DL) ${ }^{56,57}$ of $0.3924 \mu \mathrm{mol} \mathrm{L}^{-1}$ is obtained based on a $3 \mathrm{~d} /$ slope (Fig. S5 $\dagger$ ). Accord to Integrated Wastewater Discharge Standard Grade I (GB8978-2012), the total manganese content in sewage couldn't more than $2 \mathrm{mg} \mathrm{L}^{-1}$ (37 $\mu \mathrm{M})$, that means our probe was sensitive enough to detect $\mathrm{MnO}_{4}{ }^{-}$. Therefore, these sensors are responsible for micromolar determination of $\mathrm{MnO}_{4}{ }^{-}$in various samples.

Furthermore, it can be seen that the increase of $\mathrm{MnO}_{4}{ }^{-}$ concentration can not only quench the FL intensity, but also cause 

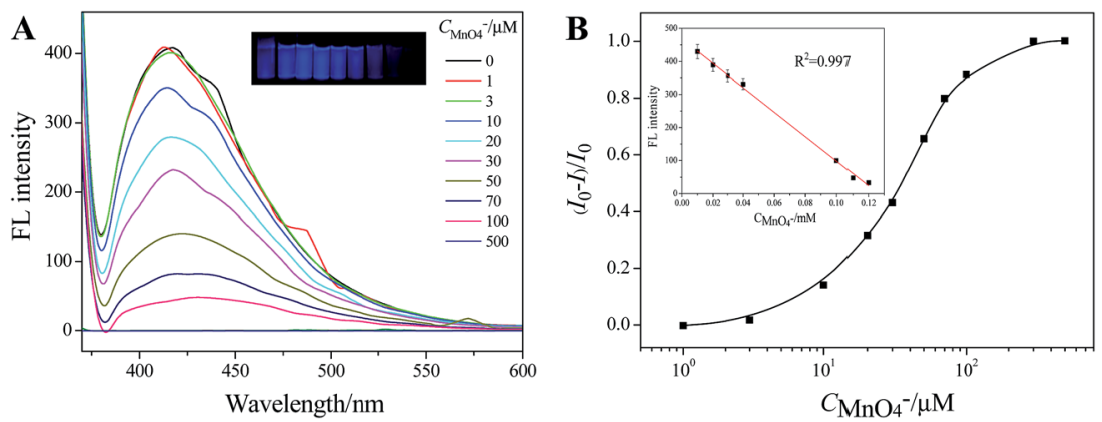

Fig. 5 (A) Fluorescence spectra of Tyloxapol $\left(3 \mathrm{mmol} \mathrm{L}^{-1}\right)$ recorded upon the addition of various amounts of $\mathrm{MnO}_{4}{ }^{-}$ions. Excitation wavelength $=360 \mathrm{~nm}$. (B) The relationship between $\left(I_{0}-I\right) / I_{0}$ and $\mathrm{MnO}_{4}{ }^{-}$from 0 to $200 \mu \mathrm{mol} \mathrm{L}{ }^{-1}$. Inset is a linear region. $I$ and $I_{0}$ are the $\mathrm{FL}$ intensities of Tyloxapol at $360 \mathrm{~nm}$ in the presence and absence of $\mathrm{MnO}_{4}{ }^{-}$, respectively.

a red-shift of the $\mathrm{FL}$ band due to the additions of $\mathrm{MnO}_{4}{ }^{-}$induce the conformation change of Tyloxapol. However, although the addition of $\mathrm{MnO}_{4}^{-}$changed the conformation of Tyloxapol and induced a red shift behavior, it did not change the aggregation behavior of Tyloxapol which are always vesicles for Tyloxapol and Tyloxapol/ $\mathrm{MnO}_{4}{ }^{-}$solutions as shown in Fig. $6 \mathrm{~A}$ and B.
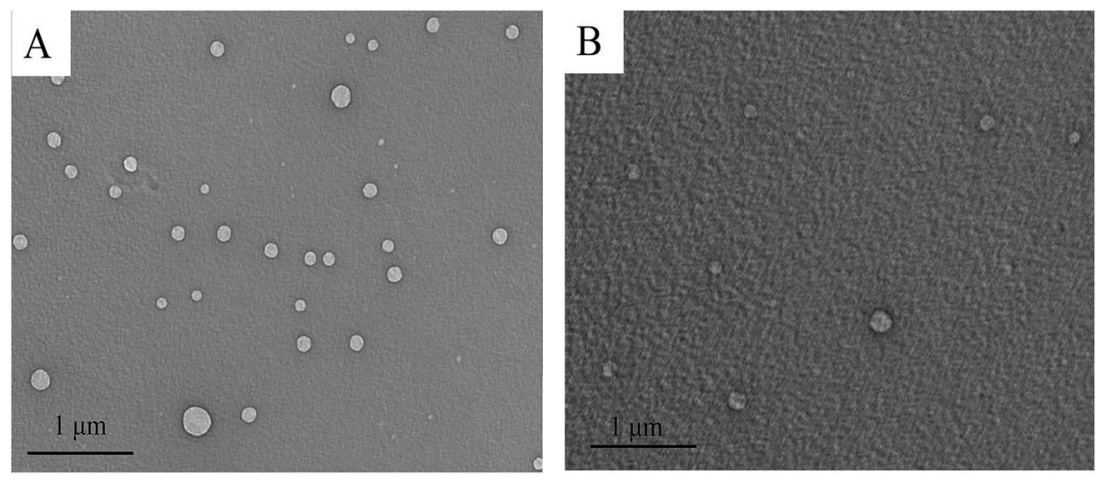

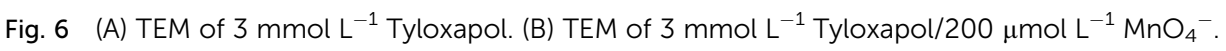
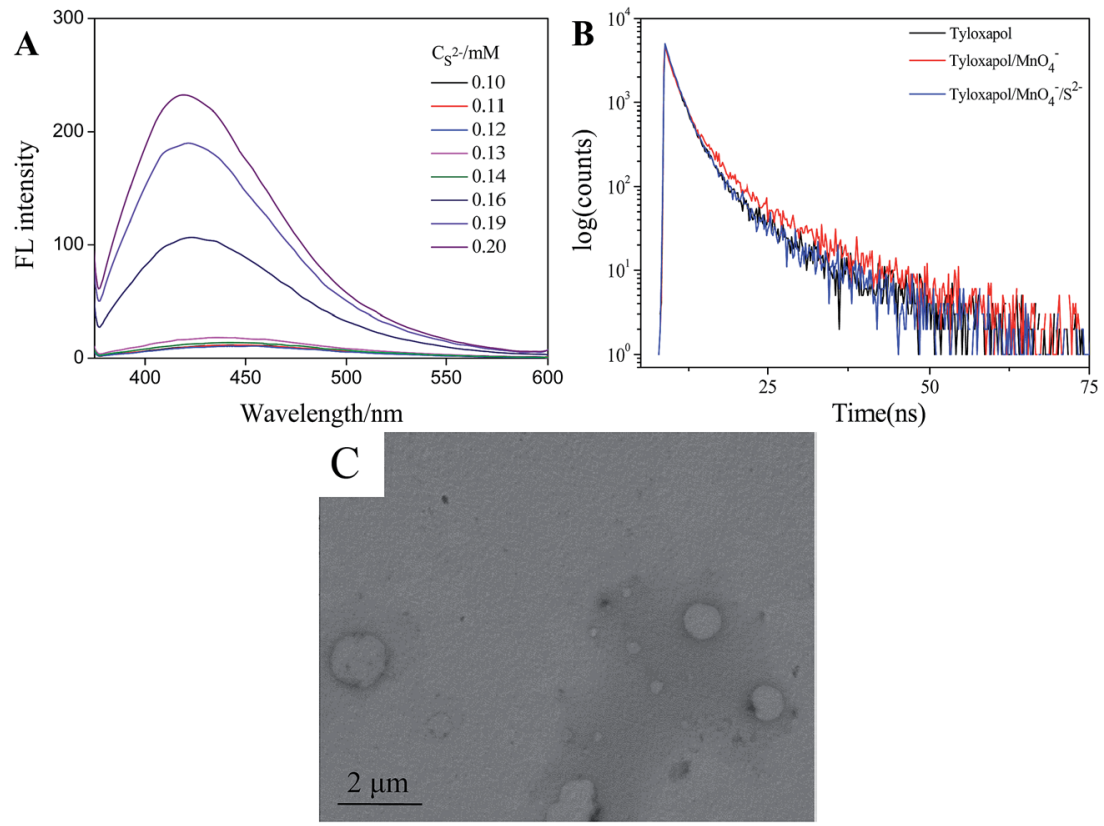

Fig. 7 (A) FL spectra of Tyloxapol $\left(3 \mathrm{mmol} \mathrm{L}^{-1}\right)+\mathrm{MnO}_{4}{ }^{-}\left(200 \mu \mathrm{mol} \mathrm{L}{ }^{-1}\right)$ recorded upon the addition of various amounts of $\mathrm{S}^{2-}$ ions. Excitation wavelength $=360 \mathrm{~nm}$. (B) Time-resolved fluorescence of Tyloxapol with an excitation at $360 \mathrm{~nm}$ in the absence (black) and in the presence of $\mathrm{MnO}_{4}{ }^{-}$(red), and $\mathrm{MnO}_{4}^{-} / \mathrm{S}^{2-}$ (blue). (C) TEM of $3 \mathrm{mmol} \mathrm{L}{ }^{-1}$ Tyloxapol/200 $\mu \mathrm{mol} \mathrm{L}{ }^{-1} \mathrm{MnO}_{4}^{-} / 500 \mu \mathrm{mol} \mathrm{L}{ }^{-1} \mathrm{~S}^{2-}$. 


\section{$\mathrm{S}^{2-}$ and aldehydes detection by Tyloxapol/ $\mathrm{MnO}_{4}{ }^{-}$platform}

Because on the above study, it has been observed that besides other anions, $\mathrm{S}^{2-}$ can recover the FL intensity of Tyloxapol. Thus, another sensing application of the Tyloxapol/ $\mathrm{MnO}_{4}{ }^{-}$ platform to probe $\mathrm{S}^{2-}$ was also investigated. We added all kinds of anions to the Tyloxapol/ $\mathrm{MnO}_{4}{ }^{-}$system, it can be observed that upon the addition of $\mathrm{S}^{2-}$, the fluorescence of Tyloxapol/ $\mathrm{MnO}_{4}{ }^{-}$could be turned on (Fig. 3B) and the reason of $\mathrm{S}^{2-}$ which makes the fluorescence turned on obviously may be because of the oxidation-reduction reaction between $\mathrm{S}^{2-}$ and $\mathrm{MnO}_{4}{ }^{-}$ $\left(2 \mathrm{MnO}_{4}{ }^{-}+5 \mathrm{~S}^{2-}+16 \mathrm{H}^{+}=5 \mathrm{~S} \downarrow+2 \mathrm{Mn}^{2+}+8 \mathrm{H}_{2} \mathrm{O}\right)$. A good linear correlation $\left(R^{2}=0.9838\right)$ is observed over the concentration range of $0.13-0.2 \mathrm{mmol} \mathrm{L}^{-1}$ and the DL could low as $0.039 \mu \mathrm{mol}$ $\mathrm{L}^{-1}$ based on a 3d/slope as shown in Fig. S4. $\dagger$ Moreover, TEM result also indicated that the addition of $\mathrm{S}^{2-}$ didn't destroy the aggregation behavior of Tyloxapol/ $\mathrm{MnO}_{4}{ }^{-}$and still remained the vesicle structure as shown in Fig. 7C. We also did the UV/vis absorption spectrum of $3 \mathrm{mmol} \mathrm{L}{ }^{-1}$ Tyloxapol/200 $\mu \mathrm{mol} \mathrm{L} \mathrm{L}^{-1}$ $\mathrm{MnO}_{4}{ }^{-} / 500 \mu \mathrm{mol} \mathrm{L}{ }^{-1} \mathrm{~S}^{2-}$, as shown in Fig. S5a, $\dagger$ there was no apparent UV/vis absorption for the sample and the FL became turn-on, which also proved that $\mathrm{MnO}_{4}{ }^{-}$could quench the fluorescence because of IFE.

To get an insight into the quenching and recovery behavior in this system, time-resolved fluorescence by the fluorescence upconversion technique have been measured. The fluorescence decay behavior of Tyloxapol were shown in Fig. 7B, and the exponential fit results are summarized in Table 1 . It can be seen that the lifetimes for pure Tyloxapol were analysed using the multi-exponential mode giving as a result two decay lifetimes of 1.7684 and $7.5899 \mathrm{~ns}\left(\chi^{2}=1.062\right)$. After the addition of $\mathrm{MnO}_{4}{ }^{-}$, the lifetime of Tyloxapol did not change significantly, the values being 1.8729 and $8.8375 \mathrm{~ns}\left(\chi^{2}=1\right)$. The addition of $\mathrm{S}^{2-}$ to Tyloxapol/ $\mathrm{MnO}_{4}{ }^{-}$solution gave similar results of 1.8017 and $7.2363 \mathrm{~ns}\left(\chi^{2}=0.997\right)$. The changes in lifetimes after the addition of these molecules indicate that the changes in FL are due to the dynamic quenching.

We also used the Tyloxapol/ $\mathrm{MnO}_{4}{ }^{-}$fluorescent probe to detect the organic pollutant. As shown in Fig. 8A, we added four kinds of conventional organic pollutants (aniline, phenol, formaldehyde and glyoxal) to Tyloxapol/ $\mathrm{MnO}_{4}{ }^{-}$ system and it can be observed that only the addition of

Table 1 Fluorescence lifetimes obtained with two-exponential fit of the fluorescence decay curves of the Tyloxapol alone, $\mathrm{Tyloxapol}^{\mathrm{MnO}}{ }_{4}{ }^{-}$, and Tyloxapol/ $/ \mathrm{MnO}_{4}{ }^{-} / \mathrm{S}^{2-}$, respectively

\begin{tabular}{lll}
\hline Sample & $\tau_{1} / \mathrm{ns}(\%)$ & $\tau_{2} / \mathrm{ns}(\%)$ \\
\hline $3 \mathrm{mmol} \mathrm{L}^{-1}$ Tyloxapol & $1.7684(80.98)$ & $7.5899(19.02)$ \\
$3 \mathrm{mmol} \mathrm{L}^{-1}$ Tyloxapol $+200 \mu \mathrm{mol} \mathrm{L}^{-1} \mathrm{MnO}_{4}{ }^{-}$ & $1.8729(79.05)$ & $8.8375(20.95)$ \\
$3 \mathrm{mmol} \mathrm{L}^{-1}$ Tyloxapol $+200 \mu \mathrm{mol} \mathrm{L}^{-1} \mathrm{MnO}_{4}{ }^{-}+500 \mu \mathrm{mol} \mathrm{L}^{-1} \mathrm{~S}^{2-}$ & $1.8017(85.21)$ & $7.2363(14.79)$
\end{tabular}
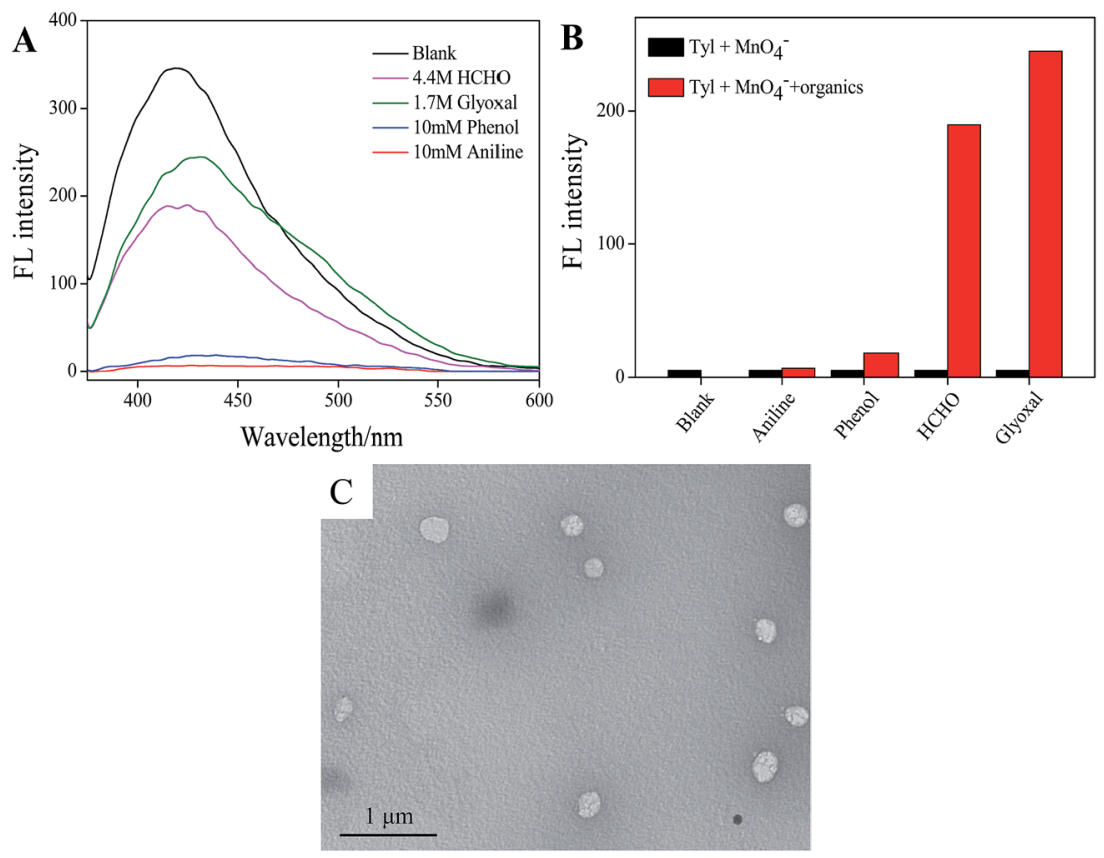

Fig. 8 (A) Fluorescence intensity of Tyloxapol $\left(3 \mathrm{mmol} \mathrm{L}^{-1}\right)+\mathrm{MnO}_{4}{ }^{-}\left(200 \mu \mathrm{mol} \mathrm{L}{ }^{-1}\right)$ recorded upon the addition of different organics. Excitation wavelength $=360 \mathrm{~nm}$. (B) Red bars represent the addition of various organic pollutant to the Tyloxapol $+\mathrm{MnO}_{4}{ }^{-}$solution and black bars represent the Tyloxapol $+\mathrm{MnO}_{4}^{-}$solutions. $C_{\text {aniline }}=C_{\text {phenol }}=10 \mathrm{mmol} \mathrm{L}{ }^{-1}, C_{\text {formaldehyde }}=4.4 \mathrm{~mol} \mathrm{~L}^{-1}, C_{\text {glyoxal }}=1.7 \mathrm{~mol} \mathrm{~L}$, excitation wavelength $=360 \mathrm{~nm}$. (C) TEM of $3 \mathrm{mmol} \mathrm{L}{ }^{-1}$ Tyloxapol/200 $\mu \mathrm{mol} \mathrm{L}^{-1} \mathrm{MnO}_{4}{ }^{-} / 4.4 \mathrm{~mol} \mathrm{~L}{ }^{-1} \mathrm{HCHO}$. 


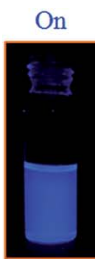

Tyloxapol

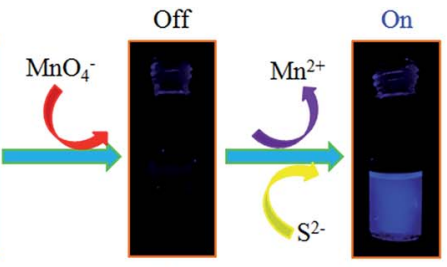

$2 \mathrm{MnO}_{4}^{-}+5 \mathrm{~S}^{2-}+16 \mathrm{H}^{+} \rightarrow 5 \mathrm{~S} \downarrow+2 \mathrm{Mn}^{2+}+8 \mathrm{H}_{2} \mathrm{O}$

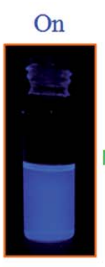

Tyloxapol

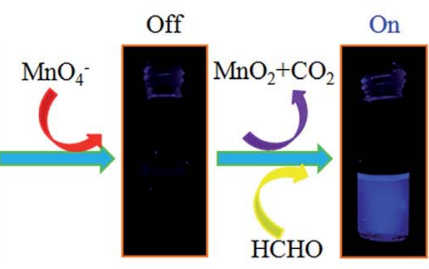

$4 \mathrm{MnO}_{4}{ }^{-}+3 \mathrm{HCHO} \rightarrow 3 \mathrm{CO}_{2} \uparrow+4 \mathrm{MnO}_{2}+4 \mathrm{OH}^{*}+\mathrm{H}_{2} \mathrm{O}$

Scheme 1 Schematic illustration of FL assays for $\mathrm{Mn}(\mathrm{VII}), \mathrm{S}(\mathrm{II})$ and aldehydes based on the IFE of Tyloxapol.

formaldehyde and glyoxal can make the quenched fluorescence turned on. This may due to the reaction between aldehyde and $\mathrm{MnO}_{4}{ }^{-}$, so that Tyloxapol molecules which were surrounded by $\mathrm{MnO}_{4}{ }^{-}$were released and the luminescence properties were recovered. From our experiment, it can be concluded that the platform of Tyloxapol/ $\mathrm{MnO}_{4}{ }^{-}$could be utilized to probe $\mathrm{S}^{2-}$ and aldehydes through the oxidationreduction reaction and some other anions and aldehydes can cause some small influences but it does not affect the detection of sulfur ions.

We also did the UV/vis absorption spectrum of $3 \mathrm{mmol} \mathrm{L}^{-1}$ Tyloxapol/200 $\mu \mathrm{mol} \mathrm{L}^{-1} \mathrm{MnO}_{4}^{-} / 4.4 \mathrm{~mol} \mathrm{~L}^{-1} \mathrm{HCHO}$, as shown in Fig. S5b, $\uparrow$ there was no apparent UV/vis absorption for the sample and the FL property of Tyloxapol turned on because of the reduction of $\mathrm{MnO}_{4}{ }^{-}$by $\mathrm{HCHO}\left(3 \mathrm{HCHO}+4 \mathrm{MnO}_{4}{ }^{-}=3 \mathrm{CO}_{2}+\right.$ $4 \mathrm{MnO}_{2}+4 \mathrm{OH}^{-}+\mathrm{H}_{2} \mathrm{O}$ ), which also proved that $\mathrm{MnO}_{4}{ }^{-}$quench the FL because of IFE. TEM result also indicated that the addition of HCHO didn't destroy the aggregation behavior of Tyloxapol/ $\mathrm{MnO}_{4}{ }^{-}$and still remained the vesicle structure as shown in Fig. 8C. We added different concentrations of HCHO to Tyloxapol/ $\mathrm{MnO}_{4}{ }^{-}$system, it can be seen that as the HCHO concentration increased, the fluorescence intensity increased as shown in Fig. S6. $\dagger$ A good linear correlation $\left(R^{2}=0.9855\right)$ is observed over the concentration range of $0.1-0.8 \mathrm{~mol} \mathrm{~L}^{-1}$ and the DL could low as $0.333 \mathrm{mmol} \mathrm{L}^{-1}$ based on a $3 \mathrm{~d} /$ slope as shown in Fig. $\mathrm{S} 7 . \dagger$ Accord to Integrated Wastewater Discharge Standard Grade I (GB8978-2012), the total sulfur and HCHO content in sewage couldn't more than $1 \mathrm{mg} \mathrm{L}^{-1}(0.03 \mathrm{mM})$ which means that our probe was not sensitive enough to detect $\mathrm{S}^{2-}$ and $\mathrm{HCHO}$ in real water. Therefore, we will improve the limit detection in our future work by changing the external conditions.

\section{Mechanism explanation}

Thus, the schematic representation of fluorescent Tyloxapol for detection of $\mathrm{MnO}_{4}{ }^{-}$and $\mathrm{S}^{2-}$ is shown in Scheme 1. First, $\mathrm{MnO}_{4}{ }^{-}$ can quench the FL of Tyloxapol due to IFE. Then, $\mathrm{S}^{2-}$ can react with $\mathrm{MnO}_{4}{ }^{-}$which can induce $\mathrm{MnO}_{4}{ }^{-}$to remove from the surface of Tyloxapol. Thus, the FL of Tyloxapol could be turned on. Therefore, by taking advantage of the observed FL change, we can fabricate a facile FL sensor that allows detection of $\mathrm{MnO}_{4}{ }^{-}$and $\mathrm{S}^{2-}$.

\section{Conclusions}

A water soluble fluorescent oligomer (Tyloxapol) was developed as a turn-off fluorescence chemosensor for detecting $\mathrm{Mn}$ (VII) ions. The results of fluorescence assay strongly suggests that Tyloxapol is more sensitive to the presence of $\mathrm{MnO}_{4}{ }^{-}$when compared to the other anions, including $\mathrm{Cl}^{-}, \mathrm{Br}^{-}, \mathrm{I}^{-}, \mathrm{NO}_{3}{ }^{-}$, $\mathrm{H}_{2} \mathrm{PO}_{4}{ }^{-}, \mathrm{HCO}_{3}{ }^{-}, \mathrm{OH}^{-}, \mathrm{ClO}_{4}{ }^{-}, \mathrm{Ac}^{-}, \mathrm{SO}_{4}{ }^{2-}, \mathrm{HPO}_{4}{ }^{2-}, \mathrm{CO}_{3}{ }^{2-}$, $\mathrm{C}_{2} \mathrm{O}_{4}{ }^{2-}, \mathrm{S}^{2-}, \mathrm{SO}_{3}{ }^{2-}$ and $\mathrm{Cr}_{2} \mathrm{O}_{7}{ }^{2-}$ under the same conditions, which demonstrated that Tyloxapol-based sensor can be used for label-free detection of $\mathrm{MnO}_{4}{ }^{-}$based on the IFE. Moreover, Tyloxapol/ $\mathrm{MnO}_{4}{ }^{-}$platform can be further used as another turnon sensing probe to detect $\mathrm{S}^{2-}$ against various other anions and aldehydes against various other organic pollutants. These results can illustrate that Tyloxapol as a fluorescent probe should have a broad range of usage in the fields of analytic determination and polluted water detection.

\section{Acknowledgements}

We gratefully acknowledge the financial support from the National Natural Science Foundation of China (21203109) and Young Scholars Program of Shandong University (2016WLJH20).

\section{References}

1 S. Kubik, Chem. Soc. Rev., 2010, 39, 3648-3663.

2 Z. C. Xu, X. Q. Chen, H. N. Kim and J. Y. Yoon, Chem. Soc. Rev., 2010, 39, 127-137.

3 N. Busschaert, C. Caltagirone, W. V. Rossom and P. A. Gale, Chem. Rev., 2015, 115, 8038-8155.

4 X. Lou, D. Ou, Q. Li and Z. Li, Chem. Commun., 2012, 48, 8462-8477.

5 C. Kong, R. Jia, Y. Zhao, J. Wang, Z. Qua and H. Zhang, RSC Adv., 2016, 6, 63548.

6 T. Gunnlaugsson, M. Glynn, G. M. Tocci, P. E. Kruger and F. M. Pfeffer, Chem. Rev., 2006, 250, 3094-3117.

7 L. E. S. Figueroa, M. E. Moragues, E. Climent, A. Agostini and R. M. Manez, Chem. Soc. Rev., 2013, 42, 3489-3613.

8 I. Ravikumar and P. Ghosh, Chem. Soc. Rev., 2012, 41, 30773098.

9 S. R. J. Oliver, Chem. Soc. Rev., 2009, 38, 1868-1881.

10 Y. Liu and X. X. Wang, Anal. Methods, 2013, 5, 1442-1448.

11 L. E. Korshoj, A. J. Zaitouna and R. Y. Lai, Anal. Chem., 2015, 87, 2560-2564.

12 U.S. Department of Health and Human Services, Toxicological Profile for Chromium; Public Health Service Agency for Toxic Substances and Disease Registry, Washington, DC, 1991.

13 M. Wu and S. Janssen, Environ. Sci. Technol., 2011, 45, 366367. 
14 B. Qiu, L. L. Xue, Y. P. Wu, Z. Y. Lin, L. H. Guo and G. N. Chen, Talanta, 2011, 85, 339-344.

15 M. R. Ganjali, V. K. Gupta, M. Hosseini, Z. R. Sarmazdeh, F. Faridbod, H. Goldooz, A. R. Badiei and P. Norouzi, Talanta, 2012, 88, 684-688.

16 B. Ding, S. X. Liu, Y. Cheng, C. Guo, X. X. Wu, J. H. Guo, Y. Y. Liu and Y. Li, Inorg. Chem., 2016, 55, 4391-4402.

17 J. W. Goode, Adv. Chem., 1985, 14, 217-227.

18 S. E. Sayed, L. Pascual, M. Licchelli, R. M. Manez, S. Gil, A. M. Costero and F. Sancenon, ACS Appl. Mater. Interfaces, 2016, 8, 14318-14322.

19 A. N. Ramdzan, M. I. Almeida, M. J. McCullough and S. D. Kolev, Anal. Chim. Acta, 2016, 919, 47-54.

20 P. Yang, C. W. Lau, J. Y. Liang, J. Z. Lu and X. Liu, Luminescence, 2007, 22, 473-479.

21 Z. Li, L. K. Jacobus, W. P. Wuelfing, M. Golden, G. P. Martin and R. A. Reed, J. Chromatogr., A, 2006, 1104, 256-262.

22 X. L. Gou, G. X. Wang, J. S. Yang, J. Park and D. Wexler, J. Mater. Chem., 2008, 18, 965-969.

23 S. Pirsa and N. Alizadeh, Sens. Actuators, B, 2010, 147, 461466.

24 T. Itoh, I. Matsubara, W. Shin, N. Izu and M. Nishibori, Sens. Actuators, B, 2008, 128, 512-520.

25 H. Tanaka and Y. Kanno, Jpn. J. Appl. Phys., Part 1, 2007, 46, 7509-7511.

26 K. Mitsubayashi, H. Matsunaga, G. Nishio, S. Toda, Y. Nakanishi, H. Saito, M. Ogawa and K. Otsuka, Sens. Actuators, B, 2005, 108, 660-664.

27 P. Jacquinot, A. W. E. Hodgson, B. Muller, B. Wehrli and P. C. Hauser, Analyst, 1999, 124, 871-876.

28 S. Iwasawa, Y. Kikuchi, Y. Nishiwaki, M. Nakano, T. Michikawa, T. Tsuboi, S. Tanaka and T. Uemura, J. Occup. Health, 2009, 51, 38-47.

29 N. Sang, Y. Yun, H. Li, L. Hou, M. Han and G. K. Li, Toxicol. Sci., 2010, 114, 226.

30 J. Flavioda, S. Petruci and A. A. Cardoso, Anal. Methods, 2015, 7, 2687-2692.

31 T. L. Guidotti, Int. J. Toxicol., 2010, 29, 569-581.

32 X. Lou, H. Mu, R. Gong, E. Fu, J. Qin and Z. Li, Analyst, 2011, 136, 684-687.

33 S. Balasubramanian and V. Pugalenthi, Water Res., 2000, 34, 4201-4206.

34 M. S. P. Silva, C. X. Galhardo and J. C. Masini, Talanta, 2003, 60, 45-52.

35 M. Colon, J. L. Todoli, M. Hidalgo and M. Iglesias, Anal. Chim. Acta, 2008, 609, 160-180.

36 B. Spilker, J. Randhahn, H. Grabow, H. Beikirch and P. Jeroschewski, J. Electroanal. Chem., 2008, 612, 121-130.
37 M. G. Choi, S. Cha, H. Lee, H. L. Jeon and S. K. Chang, Chem. Commun., 2009, 7390-7392.

38 R. F. Huang, X. W. Zheng and Y. J. Qu, Anal. Chim. Acta, 2007, 582, 267-274.

39 C. C. Wang, S. Feng, L. Y. Wu, S. Y. Yan, C. Zhong, P. Guo, R. Huang, X. C. Weng and X. Zhou, Sens. Actuators, B, 2014, 190, 792-799.

40 T. Suzuki, A. Hiolki and M. Kurahashi, Anal. Chim. Acta, 2003, 476, 159-165.

41 R. M. Manez and F. Sancenon, Chem. Rev., 2003, 103, 44194476.

42 C. Y. Lai, B. G. Trewyn, D. M. Jeftinija, K. Jeftinija, S. Xu, S. Jeftinija, V. S. Y. Lin and J. Am, J. Am. Chem. Soc., 2003, 115, 4451-4459.

43 M. Numata, C. Li, A. H. Bae, K. Kaneko, K. Sakurai and S. Shinkai, Chem. Commun., 2005, 37, 4655-4657.

44 H. S. Jung, P. S. Kwon, J. W. Lee, J. I. Kim, C. S. Hong, J. W. Kim, S. Yan, J. Y. Lee, J. H. Lee, T. Joo and J. S. Kim, J. Am. Chem. Soc., 2009, 131, 2008-2012.

45 X. Xin, Y. Y. Zhu, X. R. Cao and G. Y. Xu, J. Surfactants Deterg., 2014, 17, 71-83.

46 J. L. Shen, J. Y. Pang, T. Kalwarczyk, R. Hołyst, X. Xin, G. Y. Xu, X. Y. Luan and Y. J. Yang, J. Mater. Chem. C, 2015, 3, 8104-8113.

47 S. J. Zhu, Q. N. Meng, L. Wang, J. H. Zhang, Y. B. Song, H. Jin, K. Zhang, H. C. Sun, H. Y. Wang and B. Yang, Angew. Chem., Int. Ed., 2013, 52, 3953-3957.

48 Z. Zhao, J. W. Lam and B. Z. Tang, Soft Matter, 2013, 9, 45644579.

49 Y. Hong, J. W. Lam and B. Z. Tang, Chem. Soc. Rev., 2011, 40, 5361-5388.

50 Y. Yuan, C. Zhang, M. Gao, R. Zhang, B. Z. Tang and B. Liu, Angew. Chem., Int. Ed., 2015, 54, 1780-1786.

51 L. L. Zhao, X. Xin, P. Ding, A. X. Song, Z. C. Xie, J. L. Shen and G. Y. Xu, Anal. Chim. Acta, 2016, 926, 99-106.

52 D. W. Zhang, Z. Y. Dong, X. Z. Jiang, M. Y. Feng, W. Li and G. H. Gao, Anal. Methods, 2013, 5, 1669-1675.

53 L. Xu, B. X. Li and Y. Jin, Talanta, 2011, 84, 558-564.

54 M. Zheng, Z. G. Xie, D. Qu, D. Li, P. Du, X. B. Jing and Z. C. Sun, ACS Appl. Mater. Interfaces, 2013, 5, 13242-13247.

55 Y. Wang, M. Yu, Y. Yu, Z. Bai, Z. Shen, F. Li and X. You, Tetrahedron Lett., 2009, 50, 6169-6172.

56 F. Zhang, L. Wang, S. H. Chang, K. L. Huang, Y. Chi, W. Y. Hung, C. M. Chen, G. H. Lee and P. T. Chou, Dalton Trans., 2013, 42, 7111-7119.

57 L. N. Neupane, J. M. Kim, C. R. Lohani and K. H. Lee, J. Mater. Chem., 2012, 22, 4003-4008. 